\title{
Women rate the competence of their occupational role higher than men do: Evidence from two different samples
}

\author{
Ingrid Zakrisson ${ }^{1}$ D
}

Accepted: 14 January 2022

(c) The Author(s) 2022

\begin{abstract}
Gender stereotypes play a potent role in how the work of men and women is perceived and valued. Stereotypes also influence the way people look upon themselves. In the present research, two studies are reported where men and women at work rated the degree of warmth and competence of a person with their own occupation, and how they think people in general would perceive a person in the same occupation. A wider gap between own perceptions and that of people in general was expected for women than for men, as it was assumed that the view of other people's perceptions would serve as a proxy for stereotype threat for women. Study 1 comprised 449 participants ( $74 \%$ women) working within the public sector, mainly in social, caring, and education professions, and Study 2 comprised a convenience sample of 189 participants (70\% women) from a variety of sectors and professions. Both studies yielded consistent results; contradictory to what was expected, men and women did not differ in terms of how they thought people in general would perceive the competence of their occupation, instead women rated the competence of their own occupation higher than men did, even after controlling for type of occupation and educational level. Warmth displayed only minor gender differences. The results are discussed in relation to research on counter-reactions against stereotype threat, how the concept of competence could be understood, as well as other possible explanations of the unexpected results.
\end{abstract}

Keywords gender stereotypes $\cdot$ stereotype threat $\cdot$ occupations $\cdot$ competence $\cdot$ warmth

\section{Introduction}

A gender equal labor market is far from reality, not even in countries taking gender equality seriously. In Sweden, despite the fact that it is one of the least unequal countries in the world (rank 7; United Nations Development Programme [UNDP], 2021), women are paid less for their work. This is true even after taking into consideration factors such as age, education, part time employment, type of occupations, etc., although men and women take part in the labor force to almost the same extent (Statistics Sweden, 2018). The situation seems to be similar in many countries (Joshi et al., 2015). The suggestion that gender stereotypes play a role in this has been investigated many times (Barreto et al., 2008; Ellemers, 2018; Heilman, 2012; Heilman \& Eagly, 2008). Leadership is, for example, consistently found to be

Ingrid Zakrisson

ingrid.zakrisson@miun.se

1 Department of Psychology and Social Work, Mid Sweden University, SE-83125 Östersund, Sweden associated with men and masculinity (Hoffman \& Musch, 2019; Koenig et al., 2011; Vial et al., 2016). Female leaders are also seen as emotional and lacking emotional stability and control to a higher extent than men (Brescoll, 2016). Not only do stereotypes influence how a person is evaluated, they may also serve as a context for self-perceptions (Eagly et al., 2000). Warmth and competence are considered two main perceptual dimensions guiding the formation of impressions of other people (Fiske et al., 2007). Warmth is considered to be characteristic of female roles while competence is associated with male roles (Eckes, 2002; Fiske et al., 2002). In the present study, two investigations are presented that explore how men and women perceive their own occupational roles, and how they think that these occupations are perceived by people in general, in terms of competence and warmth. It was assumed that the view of how other people perceive their work role would serve as a stereotype threat (Steele \& Aronson, 1995) for women, due to a lack of fit between women's different roles (Eagly \& Karau, 2002).

According to the Social Role Theory (Eagly et al., 2000) it is suggested that physical sex differences, such as 
restrictions set on women due to childbirth, as well as men's greater size and strength, historically have caused a gendered division of labor. Having greater bodily strength and not being restricted by the care of young children, made it easier to perform activities giving access to resources, and thus to more power and higher status. As a consequence, what would be expected as possible and desirable behavior for men and women would differ, as would what men and women think is possible or desirable for themselves to do. Men would be supposed to take on agentic roles, taking part in activities outside the home, while women would be supposed to act in a communal way, taking part in caring and nurturance inside the home (Fiske, 2014). However, the constraints set by childbirth are less important in society today, with lower birth rates, and less dependence on maternal care for young children (Eagly et al., 2000). Furthermore, greater size and physical strength is less important nowadays, as few occupational roles today require such abilities. Yet this still causes people to associate certain roles, skills, and traits differently with men and women (Eagly et al., 2000; Ellemers, 2018).

Agency and communality can be seen as embedded in a broader perceptual space accounting for much variation in how people and groups are perceived (Fiske, 2018), not only related to gender roles. According to the Stereotype Content Model (Fiske et al., 2007), impressions of other people are formed along the dimensions of competence and warmth. Competence is built up of attributes related to ability and agency. Warmth is related to other-directedness, such as communion and morality (Fiske, 2018). In the same way that communion and agency have been found to differ in the perceptions of men and women, so do competence and warmth (Eckes, 2002; Fiske et al., 2002). This means that agentic/competent traits and behaviors are expected from any man and communal/warm traits and behaviors are expected from any woman. Accordingly, as both attributes are valued in society, and in fact, most people regard women to be nicer than men (Eagly \& Mladinic, 1994), discrimination of women does not necessarily originate from antipathy. Rather it is a consequence of a lack of fit between what is expected of a woman and what is expected of a dedicated member of the work force (Eagly \& Karau, 2002; Heilman, 2001). Displaying warmth would reduce credibility as a professional, while suppressing warmth would violate what is expected of a woman.

Gender stereotypes not only affect how men and women are perceived by others, but they also affect how people look upon themselves. Research has shown that women tend to perceive themselves as more communal than men do (Hentschel et al., 2019). Women have also been found to perceive themselves as less competent, especially in fields traditionally regarded as masculine, such as STEM fields (Tellhed et al., 2017). Having lower trust in one's competence naturally has detrimental effects, and it has been shown that being subjected to the risk of being discriminated against lowers the self-efficacy beliefs even further (Quinn et al., 2013). This phenomenon is labeled stereotype threat, which means the risk of identifying a stereotype about one's group as characteristic of oneself (Steele \& Aronson, 1995). This effect has been shown to reduce the performance of individuals from targeted groups, especially in relation to academic performance; in the case of women in relation to mathematical and spatial tasks (Hoyt \& Murphy, 2016; Quinn et al., 2013), negotiation tasks (Kray et al., 2002; Tellhed \& Björklund, 2011), leadership and managerial tasks (Bergeron et al., 2006; Hoyt \& Murphy, 2016), as well as impression management (Latu et al., 2015). Women have also been found to devaluate their contributions to collaborative work due to negative performance expectations (Haynes \& Heilman, 2013). Such threats have also been found to affect the career choices of women (Hoyt \& Murphy, 2016; Tellhed et al., 2017; van Veelen et al., 2019), entrepreneurial aspirations (BarNir, 2021) as well as work motivation and work-team identification (Veldman et al., 2017). Furthermore, being the target of stereotype threat tends to influence the psychological wellbeing (Barreto et al., 2008; Schmitt et al., 2014).

Stereotypes can be expressed both blatantly, by explicitly referring to the inferiority of women, and subtly, that is, implicitly and ambiguously displayed (Fiske, 2014), and it is these latter forms that are particularly at work instilling stereotype threat (Barreto et al., 2008; Hoyt \& Murphy, 2016). When stereotypes and prejudice are subtly disclosed the targets are met by contradicting messages - overt, verbal behavior adhering to equality principles, and covert non-verbal behavior implying the opposite. While blatant prejudice rather evokes aggression among the targets, subtle forms evoke anxiety (Barreto et al., 2008). Subtle stereotypes can take various forms, however a common characteristic is that they are expressed quite automatically and without control (Devine, 1989), for example through nonverbal behavior (Crosby et al., 1980; Fiske, 2014). They do not need an explicit sender, but are part of the context, cueing a disadvantage for the target's social identity. This could be something as simple as being a numerical minority (Hoyt \& Murphy, 2016). It could also be the norms embedded in the situation revealed in implicit ways (Meeussen et al., 2020; Veldman et al., 2017). Norms regarding gender form a particular situation for women as such biases are ambivalent (Glick \& Fiske, 2001). As mentioned above, many traits associated with women are highly valued. Benevolent sexism is aimed at women complying with traditional gender norms (being warm and communal). In combination with hostile sexism, which is directed towards women who pose a threat to the male hegemony (being competent and agentic) and is expressed in the form of negative characterizations 
of women, benevolent sexism is assumed to be particularly effective in serving to legitimize myths of gender inequality, and to justify status quo (Glick et al., 2000). By sounding "nice" and putting women in a positive light, benevolent sexism functions in a subtle way, as it may be harder to identify as sexism. It has been demonstrated that women tend to define themselves in relational terms when exposed to benevolent sexism, especially when benevolent sexism is coming from persons with whom they expected to collaborate (Barreto et al., 2010).

It is however not enough for a subtle bias to be "in the air", a targeted person must also sense that the stereotype is applicable to them, in order for a stereotype threat to occur (Quinn et al., 2013). Consequently, a person must consider themselves as a member of the group that the prejudice is directed at and also experience that it threatens their identity (Fiske, 2014). This implies that the more a person identifies with the group, the higher the risk for stereotype threat (Fiske, 2014; Quinn et al., 2013). This is indeed what has been found, at least regarding outcomes related to various forms of performance (see Quinn et al., 2013) and career aspirations (van Veelen et al., 2019).

Stereotype threats are situation-specific (Hoyt \& Murphy, 2016) and depend on the specific cues in a particular context. This implies that any person can be the victim of stereotype threat under certain conditions. It has, for example, been found that when primed with female-stereotypical skills, men's ability decreased (Koenig \& Eagly, 2005; Kray et al., 2002). Tellhed and Adolfsson (2018) found that both men and women were affected in the same way under stereotype threat, decreasing the relationship between actual performance on an academic test and their assessment of their performance. A German study (Latsch \& Hannover, 2014) investigated the impact of medial portrayals of boys as academic failures, and found that it decreased boys' performance and increased girls'. Thus, even non-stereotyped (or positively stereotyped) groups, such as men, are under certain circumstances affected by stereotype threat when primed with stereotype-relevant cues. There is also evidence that suggests a stereotype lift effect for such groups, that positively stereotyped groups fare better when cued with negative stereotype information of the outgroup (Chalabaev et al., 2008; Marx \& Stapel, 2006).

Occupations are highly gender-typed and associated with attributes related to gender stereotypes of communion/warmth and agency/competence (Froehlich et al., 2020; Haines et al., 2016; Koenig \& Eagly, 2014). Furthermore, work roles also form an aspect of our social identity, and activation of stereotype threats might influence how we perceive our own occupational role. As mentioned above, it has been suggested that there is a lack of fit, or congruence, between women's different roles in the eye of the perceiver (Eagly \& Karau, 2002; Heilman, 2001), causing more tension between their own and other people's views of them as professionals, which probably increases the more a woman identifies with her job. In the present two studies, the perception people have of their own occupational roles and their view of how people in general perceive their occupations in terms of competence and warmth was investigated. Assuming that women experience stereotypic expectations from their environment, this could lead to a fear that other people look down on their performance as professionals. Hence, it could be expected that women would think that people in general perceive their work role as less competent that men would.

There is research indicating that women themselves, due to stereotype threat, would think less of their professional competence than men do, at least in male coded domains, while men tend to think that they can manage both male and female coded domains equally well (Bench et al., 2015; Tellhed et al., 2017). However, a thorough meta-analysis of gender stereotypes in the US during the last 60 years (Eagly et al., 2019) reveals changes that correspond to women's increasing employment - competence was increasingly seen as more characteristic of both men and women. Accordingly, if the same development is mirrored in people's own perceptions, men and women would not differ in the perception of their own occupations. On the other hand, if differences do exist, they probably would be in men's favor.

There may also be barriers for men to enter traditionally female roles and occupations, which would supposedly reflect a mirrored situation with a lack of fit between what is expected of a man and what is expected of a caring and communal role. However, this situation is much less investigated, although it probably is as associated with norms and stereotypes as it is for women (Meeussen et al., 2020). Although there is research indicating changes in people's perception of gender-typed attributes in a gender equal direction, this is not the case for female coded domains. Haines et al. (2016) found that the mean levels of the probability that a certain attribute was characteristic for either a man or a woman decreased from 1983 to 2014, although the gaps in perceptions were constant. The exception was female gender roles that showed an increase in gender stereotyping. The meta-analysis presented above (Eagly et al., 2019) revealed increased gender stereotyping of communion across time, while male stereotyping of agency was stable. As female related attributes seem to increase in gender stereotyping, this would suggest a mirrored effect for men, regarding warmth, that the gap between own perception and the view of how other people would perceive their occupation would be wider for men than for women, due to men expecting people to value their level of warmth lower than women would. However, as it has been found that for normally positively stereotyped groups, group identity is not as salient as for negatively stereotyped groups (Marx \& Stapel, 2006), it is 
equally likely that men would not experience a stereotype threat regarding warmth, unless they are working within a female-dominated occupation, which would make their own gender more salient (Hoyt \& Murphy, 2016).

\section{Study 1}

The first study constitutes a part of a work environment investigation among younger employees ( $\leq 30$ years) within local authorities on a municipality level (the smallest administrative level in the Swedish public sector). Authorities at the municipality level provide main welfare services such as elderly care, social services, childcare, and primary and secondary education. In addition, although smaller in terms of staffing, they also have the authority over societal planning, water supply, and maintenance of the local environment. Thus, the main activities and occupations are female dominated (such as social workers, teachers, caring occupations), while a minor part is male dominated (such as engineers and technicians).

The number of women within the work force increased during the nineteen seventies and nineteen eighties, as the public sector grew, mainly by providing welfare services such as health care, childcare, elderly care. At the same time, there was a development of professionalization of working life, in that higher levels of education increasingly became required in many professions (Statistics Sweden, 2018). This indicates increased competence in an objective sense, and specifically so in the welfare sector. This covariation would to some extent be reflected in people's perceptions (Eagly et al., 2019). Consequently, it was considered important to control for educational level in the analyses.

\section{Method}

\section{Participants}

There was a total of 449 participants ( $74 \%$ women, nine persons did not indicate their gender, or chose "other"), younger employees (up to the age of 30 years) all working within municipality services, in seven municipalities within one of the 21 regions in Sweden. The mean age was $26(S D=2.74$, ranging from the age of 19 to 31 ). The majority (52\%; 34 men and 184 women) worked within caring/social occupations, $26 \%$ (28 men and 82 women) in school, $14 \%$ (9 men and 47 women) with administration and $9 \%$ (27 men and 11 women) within technical occupations. Almost half of the sample (44\%) had a university education.

The response rate was $19 \%$, ranging between 16 and 33 $\%$ within each subsample (municipality). Due to the low response rates, comparisons between actual and intended samples were made where possible. These analyses showed that the gender and age distributions did not differ significantly. There were some differences in terms of form of employment and occupational field, but these did not display any systematic pattern.

\section{Procedure}

The web-based questionnaire was distributed to the participants via their company e-mail. In one municipality (comprising about $6 \%$ of the total sample), where not all employees had access to (or used) the e-mail system, the questionnaire was sent by mail to their workplace addresses. The e-mail addresses (and conventional addresses) were obtained from the HR department in each municipality.

The questionnaire started with a cover letter describing the aim of the study, how the study was carried out and how data was to be handled and reported. It was stressed that participation was voluntary and anonymous. It was explicitly mentioned that by turning to the next page (or returning the paper version of the questionnaire in the pre-paid envelope) they consented to participation.

\section{Instrument}

The present study was part of a general work environment investigation, carried out in collaboration with the municipalities' HR departments. The main part of the questionnaire contained questions related to the psychosocial work environment and covered areas such as work demands, control, social support, work-private life conflict, and general wellbeing. The results regarding these parts of the questionnaire are reported elsewhere. In addition, one question asked: "How do you look upon a person with your occupation?" This question was assumed to highlight their social identity as a professional rather than their personal identity. It was also considered important to design the question as gender-neutral as possible, in order not to impose any gender stereotypes on the participants. If any gender-stereotypical responses would appear, they should emanate from the participants themselves. Another question asked: "How do you perceive that people in general in society look upon a person with your occupation?" The rationale behind this formulation was that it was assumed that the view of how other people perceive the competence of their work role would serve as a stereotype threat (Steele \& Aronson, 1995) for women, due to a lack of fit between women's different roles in society (Eagly \& Karau, 2002). Six items related to the Stereotype Content Model (SCM; Fiske, 2018) measuring competence and warmth were used. For competence these items were: competent, skilled, and efficient, and for warmth: warm, friendly, and sincere, presented in a random order. These items were answered on a five-step scale, ranging from (1) not at all, to (5) very much. Four variables 
were constructed as a mean value across the defining items; Own perception of competence (Cronbach's $\alpha=.83$ ), Own perception of warmth (Cronbach's $\alpha=.77$ ), View of the perception of competence by people in general (Cronbach's $\alpha$ $=.80)$, and View of the perception of warmth by people in general (Cronbach's $\alpha=$.74).

\section{Results}

In order to test the hypotheses, two three-way mixed analyses of variance (for competence and warmth separately) were carried out with the comparison between own perception and perception of people in general as a within-subject variable and gender and educational level (high school vs. university) as between-groups variables. Turning first to competence, Levene's test of equality of error variance was significant for own perception, however Hartley's $F_{\text {max }}$ test (Glen, 2020) revealed a variance ratio between highest and lowest variance below the critical value (1.96), therefore the analysis was retained. There was a significant main effect for the comparison between own perception and the view of other people's perception, $F(1,436)=273.80, p<.001, \eta^{2}$ $=.39$. The participants perceived a person with their own occupation as more competent $(M=4.22, S D=0.68)$ than they considered such a person to be perceived by people in general $(M=3.27, S D=0.84)$. There were also significant main effects of gender, $F(1,436)=7.14, p<.01, \eta^{2}=.02$, and educational level, $F(1,436)=11.89, p<.01, \eta^{2}=$ .03 , although these effects were considerably lower. Women rated the competence of their work role (both in own eyes and in the eyes of other people) somewhat higher $(M=3.79$, $S D=0.60)$ than men $(M=3.61, S D=0.60)$. People with a university education rated the competence higher $(M=3.89$, $S D=0.58)$ than people with a high school education $(M=$ 3.64; $S D=0.60)$. These effects were qualified by significant interaction effects for the comparison between self and others' perception and gender, $F(1,436)=10.86, p<.01, \eta^{2}$ $=.02$, and for the comparison between self and others' perception and educational level, $F(1,436)=8.82, p<.01, \eta^{2}$ $=.02$. As can be seen in Table 1 , and which a simple effects analysis confirmed, women perceived a person in their own occupation as more competent than men did, regardless of educational level, $t(438)=4.54, p<.001$, Cohen's $d=0.51$. The difference between men and women in how they thought people in general would perceive a person with their occupation was not significant, $t(438)=0.25, p>.05$, Cohen's $d$ $=0.03$. Simple effects analysis also revealed that (regardless of gender) people with a university education rated the competence of a person with their own occupation higher than people with a high school education, both in their own eyes, $t(438)=2.01, p<.05$, Cohen's $d=0.19$, and in the eyes of people in general, $t(438)=4.42, p<.001$, Cohen's $d=0.42$, although the effect size was considerable larger for how they thought people in general perceived their occupation than for their own perception. The interaction between gender and educational level was not significant, $F(1,436)$ $=0.05$, nor was the three-way interaction, $F(1,436)=2.41$.

As mentioned above, due to the development of the labor market, men and women tend to work in different types of occupations. Furthermore, due to these trends it would also be possible that men and women differ in terms of educational level. $\chi^{2}$-analyses revealed no gender differences regarding educational level, $\chi^{2}(1)=0.11, p>.05$, but significant gender differences for type of occupation, $\chi^{2}(3)$ $=57.78, p<.001$. Men were overrepresented in technical occupations (standardized residual, $S R=6.1$ ) and underrepresented in caring and social occupations $(S R=-2.3)$, while women were underrepresented in technical occupations ( $S R$ $=-3.4$ ). Administrative and educational occupations did not display any substantial gender differences (SRs 1.1 and lower). A similar analysis as the one presented above for those types of occupations with a reasonable number of both men and women and dominated by women (i.e, caring/social and school professions, $n=328$ ) was carried out. This analysis confirmed the above reported pattern, with the exception that no significant main effect of gender was found. Women still regarded their own occupation as characterized more by competence than men did, while men and women did not differ in how they thought people in general look upon their occupation.
Table 1 Own perceptions and view of other people's perceptions of one's own occupation as a function of gender and educational level $(N$ $=440$ ).

\begin{tabular}{|c|c|c|c|c|}
\hline & & \multicolumn{2}{|l|}{ Cell means } & \multirow{2}{*}{$\begin{array}{l}\text { Marginal } \\
\text { means } \\
\text { Gender }\end{array}$} \\
\hline & & Own perception & Perception of others & \\
\hline & & $M(S D)$ & $M(S D)$ & $M(S D)$ \\
\hline \multirow[t]{2}{*}{ Men } & High school & $3.98(0.61)$ & $3.07(0.80)$ & \multirow{2}{*}{$3.61(0.60)$} \\
\hline & University & $3.96(0.72)$ & $3.51(0.76)$ & \\
\hline \multirow[t]{2}{*}{ Women } & High school & $4.23(0.74)$ & $3.14(0.84)$ & \multirow{2}{*}{$3.79(0.60)$} \\
\hline & University & $4.40(0.55)$ & $3.46(0.82)$ & \\
\hline \multirow{2}{*}{$\begin{array}{l}\text { Marginal means } \\
\text { Education }\end{array}$} & High school & \multicolumn{2}{|c|}{$3.64(0.60)$} & \\
\hline & University & \multicolumn{2}{|c|}{$3.89(0.58)$} & \\
\hline
\end{tabular}


As for the perception of warmth, the only significant effect found was for the comparison between own perception and the assumed perception of people in general, $F$ $(1,436)=85.86, p<.001, \eta^{2}=.16$. The participants perceived a person with their own occupation as warmer $(M=4.18, S D=0.67)$ than they assumed people in general do $(M=3.75, S D=0.74)$. An analysis of participants working in caring/social and educational occupations did not change the pattern.

\section{Discussion}

The general picture here was that women regarded their own occupation as being associated with more competence than men did, even when they worked within the same kind of occupations, but that men and women did not differ in terms of how they thought people in general would perceive their occupation. This is quite contrary to what was expected. It was assumed that women would consider people in general to think less of their occupation, in terms of competence, than men would, as it has been suggested that there is a perceived lack of fit between women's different roles (Eagly \& Karau, 2002; Heilman, 2001). A lack of fit was indeed found among women, but in the opposite direction from expected. It was not the ratings of how they thought that other people would perceive their occupations that was low, it was the ratings of how they themselves perceived their occupations that were high.

For warmth there were no effects worth mentioning, neither in the expected way, nor mirrored for men in the same way as for women regarding competence, and not when controlling for type of occupation. The only significant effect was that the participants perceived a person with their own occupation as warmer than they thought that people in general do. It seems that being a minority of men among a majority of women did not render enough salience to evoke a group identity for men (Hoyt \& Murphy, 2016). It is of course also possible that there does not exist any tension between male characteristics and working in female dominated occupations.

In the present study, the participants worked within one specific sector, local authorities within the public sector, although they worked in a variety of occupations. They were also quite young, not older than approximately 30 years. It was therefore decided to replicate the investigation with people from various sectors in the labor market, both public and private, with a greater variety of occupations, and representing a wider age span. By doing so it would be possible to investigate if the pattern found was only true for a quite narrow segment of the labor market, or if it would hold also in a sample more resembling the general work force.

\section{Study 2}

The main objective in this study was to replicate the previous study, and to find out if the unexpected results found for competence would hold in a more varied sample of people within the work force. Furthermore, the aim was to see if a more varied sample would generate any effects for warmth as well.

\section{Method}

\section{Participants}

The sample comprised 189 participants (70\% women, 6 persons did not indicate their gender) with a mean age of $38(S D=12.08$, ranging from 19 to 62 years). The occupations were categorized into administration and commerce (51\%), social/health/school (33\%), and technical (16\%). Fifty-three percent had some form of university education. Men and women differed to some extent regarding type of occupation, $\chi^{2}(2)=22.98, p<.001$. Men were overrepresented in technical occupations (standardized residual, $S R$ $=3.7$ ) and slightly underrepresented in social/health/school occupations $(S R=-1.6)$. Women were underrepresented in technical occupations $(S R=-2.3)$ and slightly overrepresented in social/health/school occupations $(S R=1)$. Men and women were quite evenly distributed in administrative and commercial occupations. Men and women did not differ in terms of educational level, $\chi^{2}(1)=0.20, p>.05$. The mean age was evenly distributed across the various types of occupations, even when controlling for gender, $F \mathrm{~s}(2,171)$ $<1.00$

\section{Procedure}

The investigation was carried out through a web-based questionnaire. The link to the questionnaire was distributed to a convenience sample through social media, and through e-mails to employees within organizations.

The questionnaire started with a cover letter describing the aim of the study, how the study was carried out and how data was to be handled and reported. It was stressed that participation was voluntary and anonymous. It was explicitly mentioned that by turning to the next page of the questionnaire they consented to participation.

\section{Instrument}

The main part of the questionnaire contained questions related to the psychosocial work environment and covered areas such as work demands, control, social support, 
work-private life conflict, and general wellbeing. The results concerning these parts are not reported here. The same questions as in Study 1 were used: "How do you look upon a person with your occupation?" and: "How do you perceive that people in general in society look upon a person with your occupation?" Six items related to the Stereotype Content Model (SCM; Fiske, 2018) measuring competence and warmth were used. For competence these items were: competent, skilled, and efficient, and for warmth: warm, friendly, and sincere, presented in a random order. These items were answered on a five-step scale, ranging from (1) not at all, to (5) very much. Four variables were constructed as a mean value across the defining items; Own perception of competence (Cronbach's $\alpha=.80$ ), Own perception of warmth (Cronbach's $\alpha=.76$ ), View of the perception of competence by people in general (Cronbach's $\alpha=.83$ ), and View of the perception of warmth by people in general (Cronbach's $\alpha$ $=.77)$.

\section{Results}

As before, mixed analyses of variance with the difference between own perception and that considered to be the view of people in general as a within-subject variable, and gender and educational level as between-group variables were carried out. For competence, once again Levene's test of equality of error variances was significant for own perception, however Hartley's F $_{\text {max }}$ test (Glen, 2020) revealed a variance ratio between highest and lowest variance below the critical value (of 1.96), so it was decided that the analysis should be retained. Again there was a significant main effect for the difference between own and the perception of others' views, $F(1,176)=79.18, p<.001, \eta^{2}=.31$. The participants perceived a person with their own occupation as more competent $(M=4.48, S D=1.06)$ than how they thought people in general do $(M=3.53, S D=0.92)$. There was also a significant main effect of educational level, $F$ (1, 176) $=4.87, p<.05 ; \eta^{2}=.03$, where those with a university education rated competence higher $(M=4.16, S D=0.84)$ than people with a high school education $\operatorname{did}(M=3.82$, $S D=0.78$ ). More importantly, there was again a significant interaction effect for the comparison between own and the assumed perception of other people and gender, $F(1,176)$ $=7.04, p<.01, \eta^{2}=.04$. As can be seen in Table 2, and simple effects analysis confirmed, while women perceived a person with their own occupation as more competent than men did, $t(103.44)=2.49, p<.05$, Cohen's $d=0.38)$, no significant difference was found between men and women regarding their view of the perceptions of people in general, $t(181)=-0.94, p>.05$, Cohen's $d=0.16$. All other effects were non-significant ( $F$ s ranging between 0.14 and 0.56 ).

In order to control for the gender composition of different occupations, a mixed analysis of variance was carried out, in the same way as before, but with occupational field (social/health/school occupations, technical occupations, and administrative/commercial occupations) added as an independent variable. The analysis yielded the same pattern: A significant main effect for the difference between own and the perception of others' views, a significant main effect for educational level, and a significant interaction between gender and the comparison between own and the assumed perception of other people. Occupational field displayed only small effects, both as main effect and in interaction with the other variables ( $F$ s ranging between 0.04 and 2.50).

For warmth, two of the effects were significant. As in Study 1, the difference between own perception and the assumed perception of people in general was significant, $F$ $(1,176)=40.90, p<.001, \eta^{2}=.19$. A person with one's own occupation was considered as warmer $(M=4.07, S D$ $=1.02$ ) than what was considered to be the perception of people in general $(M=3.48, S D=0.88)$. There was also a significant main effect of gender, $F(1,176)=8.11, p<.01$, $\eta^{2}=.04$. Women both perceived themselves, and believed that other people perceive, a person with their occupation as warmer $(M=3.87, S D=0.81)$ than men $\operatorname{did}(M=3.48, S D$ $=0.70)$. All other effects were small, $F$ s ranging between 0 and 1.11 .

Adding occupational field as an independent variable, revealed again a significant main effect of the difference between own perception and the assumed perception of other people. However, the main effect of gender was no longer significant. Instead a significant effect of occupational field
Table 2 Own perceptions and view of other people's perceptions of one's own occupation as a function of gender and educational level $(N$ $=183$ ).

\begin{tabular}{|c|c|c|c|c|}
\hline & & \multicolumn{2}{|l|}{ Cell means } & \multirow{2}{*}{$\begin{array}{l}\text { Marginal means } \\
\text { Gender }\end{array}$} \\
\hline & & Own perception & Perception of others & \\
\hline & & $M(S D)$ & $M(S D)$ & $M(S D)$ \\
\hline \multirow[t]{2}{*}{ Men } & High school & $4.03(0.84)$ & $3.53(0.74)$ & \multirow{2}{*}{$3.91(0.78)$} \\
\hline & University & $4.36(1.00)$ & $3.69(1.09)$ & \\
\hline \multirow[t]{2}{*}{ Women } & High school & $4.36(1.13)$ & $3.34(0.87)$ & \multirow{2}{*}{$4.03(0.83)$} \\
\hline & University & $4.77(1.02)$ & $3.63(0.95)$ & \\
\hline \multirow{2}{*}{$\begin{array}{l}\text { Marginal means } \\
\text { Education }\end{array}$} & High school & \multicolumn{2}{|c|}{$3.82(0.78)$} & \\
\hline & University & \multicolumn{2}{|c|}{$4.16(0.84)$} & \\
\hline
\end{tabular}


was found, $F(2,165)=6.01, p<.01, \eta^{2}=.07$. People working in social, health and school professions rated their own occupation (both in their own eyes and what they considered people in general to think) higher in warmth $(M=4.03, S D$ $=0.75)$ than people in technical occupations $(M=3.37, S D$ $=0.55)$ and people in administrative and commercial occupations $(M=3.69, S D=0.83)$. The latter two categories did not differ significantly.

\section{Discussion}

Again, women were found to perceive a person with their own occupation as more competent than men did. There was also here a wider gap between one's own view and the view of the perceptions of people in general among women, although this was quite opposite to what was originally expected. It was not that they rated other people's perceptions as lower; instead, their own ratings were higher. This second study contained a wider array of occupations, although the sample size was smaller. Adding occupational filed to the analysis did not change the picture. The same pattern as in Study 1 emerged.

A difference in comparison with Study 1 was that men and women in Study 2 differed in their perceptions of warmth - men considered people in their own occupation as less warm than women did. Adding occupational field into the analysis changed this picture. The main effect of gender disappeared; instead, there was a main effect of occupation, with people working in social, health and school occupations (regardless of gender) rating their work role as warmer than the other two groups. This seem to indicate that there is a different dynamic behind the perceptions of warmth than for competence, where occupational field did not show any effect. Rather than being evoked by their gender identity, the perceptions of warmth seemed to depend on the participants' occupational role identity, as also men in these kinds of occupations rated the work roles as equally warm as women did.

\section{General Discussion}

The dominating result from these two studies was that women rated the competence of their own occupation higher than men did, while their view of how other people perceived their occupation did not differ from men's view. This was contrary to what was predicted; it was not their ratings of other people's perceptions that were lower, it was their own ratings that were higher. This pattern remained when controlling for educational level and area of work.

The starting point for this research was an assumption that, due to a lack of fit between what is expected of the role as a woman and what is expected of the role as a professional (Eagly \& Karau, 2002), women would experience a stereotype threat in their professional role (Steele \& Aronson, 1995). This would be based on a fear that other people think they are not competent enough. However, the results did not lend any support for this at all. The explanation seems to be found elsewhere. Are the results to be interpreted as some kind of reactance to stereotype threat, or is it not a question of stereotype threat at all? Are there realistic differences between men's and women's work and work conditions that might explain the unexpected results? Or is it the other way around, that men underestimate the competence of their occupational role?

\section{Stereotype Threat or Not?}

That women rated the competence of their occupational role higher than men did could be interpreted as a way of overcoming the perils of stereotype threat. This could be done by engaging in counter stereotype behavior, as a reactance to stereotype threats (Bonnot \& Jost, 2014; Hoyt \& Blascovich, 2007). This would happen if gender stereotypes were explicitly made salient. Assuming that there is a tension between traditional female roles and professional roles (Eagly \& Karau, 2002), perhaps this makes women more aware of possible risks of discrimination, which is deemed important to forego and forearm, one way being to boost one's competence. A related way of dealing with stereotype threat could be through self-affirmation (Martens et al., 2006; Sherman et al., 2013). It has been shown that the performance improved for groups that are targets of stereotype threats, when self-affirming a valued attribute compared to a group of controls not self-affirming, while no such effect was found for non-targets. It is possible that boosting the competence level of one's own group would serve as selfaffirmation, which men do not need. A third way of dealing with stereotype threat would be through role models. It has been found that learning about a successful woman in the same area (Marx et al., 2005; McIntyre et al., 2003) or being primed with a positive identity (McGlone \& Aronson, 2007) can subdue the negative effects of stereotype threat. Given that women may experience a tension between traditional and professional roles (Eagly \& Karau, 2002), perhaps there is a need for women to look for positive role models in their working life.

However, these forms of strategies to decrease the detrimental effects of stereotype threat has mainly focused on how to close the gap. As far as one knows, no research has tried to identify under which circumstances a targeted group can be led to boost their performance, competence beliefs, self-efficacy, etc. Experimental research in this vein would be highly informative. 
Of course it is possible that the results found in the present two studies do not have to do with stereotype threat at all. It was assumed that a stereotype threat would materialize as lower ratings for how they thought people in general perceive a person with their occupation. That men and women did not differ in their response to this question corresponds to a non-threat situation. Furthermore, to be a woman and to work in a female dominated occupation, which many of the women in the present two studies did, is perhaps not experienced as a conflict and hence does not pose a stereotype threat, as such occupations involves caring, nurturing, etc., behaviors that conventionally has been associated with the traditional role of a woman. Finally, the participants in these studies were not explicitly asked to rate their own competence, instead they were asked to rate the competence of a person with their own occupation. The reason for this was to highlight their social identity as a professional. It is of course possible that this instruction was too weak to elicit this identity.

Nevertheless, the suggested interpretations of the results above would explain why men and women would not differ in the perceptions of their own occupational roles; they do not explain why women perceive their work role as more competent than men do.

\section{Are There Realistic Differences in Competence Between Men's and Women's Work?}

At the same time as women increasingly have entered the paid work force, the labor market has also changed due to a growing sector of welfare services (Statistics Sweden, 2018). Another trend is an increased professionalization of the labor market, with more occupations requiring higher education. Occupations that are female dominated are mainly found in the welfare sector, often requiring a certain amount of formal education, often a university degree, such as nurses, teachers, social workers, etc. Statistics also show that in Sweden people working in occupations highly dominated by women have a higher mean educational level, with no gender differences, while in highly male dominated occupations women display a higher mean educational level than men (Zakrisson \& Löfstrand, 2019). Given that education thus can be regarded as an indicator of the objective competence of an occupation, and that the men and women participating in these studies to a dominating degree have made gender stereotypical choices of occupations, the higher ratings by women may reflect objective differences between male and female dominated occupations. However, when controlling for type of occupation, the same pattern remained; women rated the competence of their work role higher in competence than men did in the same kind of occupations.

The previously mentioned meta-analysis of gender stereotypes in the US during the last 60 years (Eagly et al.,
2019) reveals changes that correspond to women's increasing employment - women seemed to gain in both communion and competence. This meta-analysis also revealed that gender stereotypes were remarkably consistent regardless of demographic groupings such as gender. Also in Sweden people's perceptions of male and female dominated occupations seem to correspond to these differences - female dominated occupations are perceived as characterized by the same level of competence as male dominated occupations, but as warmer, while highly male dominated occupations are viewed as competent but less warm (Zakrisson \& Löfstrand, 2019).

It could thus be possible that women actually regard themselves as more competent in their professional roles than men, not as a reaction to possible discrimination, but as a fact. The meta-analysis by Eagly et al. (2019) revealed not only that competence was increasingly seen as more characteristic of both men and women, an increasing proportion of people also perceived that competence was more characteristic of a woman than of a man. Conventionally competence is seen as being built up by various forms of knowledge and skills (Eagly et al., 2019; Fiske, 2018). As there has been an increased professionalization of both male and female dominated occupations, there is no reason to expect differences in how people perceive such roles in terms of competence in this respect. However, as many female occupations are found within the welfare sector, with work directed at other people, most often in weak positions, such as children, elderly people, patients, and clients, other kinds of qualifications are also needed, such as other-directedness and empathic abilities. Perhaps women add such aspects into the perceptions of their occupations. Thus, a reasonable question is what the connotations are for the concept of competence among men and women. Do men and women actually mean the same thing when they use the concept of competence? The results from the present study suggest that it is possible that men and women conceive of the concept differently when applied to circumstances with which they are themselves familiar and perhaps identify with. Research that shed light over if, and in what possible ways, men and women conceive of the qualifications needed in their own occupational realm would be of interest.

\section{Do Men Underestimate the Competence of Their Own Occupational Role?}

Another suggestion could be that the higher ratings of competence among women reflect a realistic view, and that men underestimated the competence of their own occupation. This would happen if they were expected to be the target of stereotype threat, which might be the case if they work within a female dominated occupation, which would make their own gender more salient (Hoyt \& Murphy, 2016). In 
this case, men would score lower when working in female dominated occupations, such as social, caring, and educational occupations, but not in the other situations, however this was not what was found. Men did score lower in the perceptions of their occupational role compared to women when working in female domains, but not lower than men in the whole sample (Study 1), and occupational field did not contribute to the picture when added to the analysis (Study 2). Furthermore, it has previously been shown that men tend to think highly of their ability to manage both female and male dominated domains equally well (Bench et al., 2015; Tellhed et al., 2017).

In addition, similar patterns would have been expected for warmth for female dominated areas of work, but no differences at all were found between men and women regarding this. The only significant gender effect for warmth was that men in Study 2 rated a person with their own occupation as less warm than women did, a difference that disappeared when adding occupational field to the analysis. Instead, there was a significant main effect of occupational field, with both men and women rating their occupational role equally warm in the same kind of occupations. The highest ratings were found for occupations in the field of health, social and educational professions. This results seem to indicate a different dynamic behind the perceptions. In contrast with competence ratings, which consistently were dependent on the gender roles, for warmth they seem more associated with the occupational role, regardless of whether it is upheld by a man or a woman. However, it is less evident what to expect regarding how men in traditionally female roles are to be perceived. On one hand, norms about gender and manhood prevent men from engaging in communal behaviors (Meeussen et al., 2020). On the other hand, there is some experimental research indicating that men seem to gain from displaying warm behaviors, by being more positively evaluated than women presented in the same way (Cuddy et al., 2004; Heilman \& Okimoto, 2008). Men also tend to regard themselves as more communal compared to how they regard men in general (Hentschel et al., 2019). They are also less prone to be the target of stereotype threat (Marx \& Stapel, 2006) being a normally positively stereotyped group. It is also worth noting that the power of this analysis is not very strong. More research is thus needed, with reasonable sample sizes, to investigate the dynamic behind self-perceptions of warmth.

\section{Methodological Considerations}

In the present research the participants were not explicitly asked to rate their own competence, neither as an individual, nor as a professional, which might be a limitation. The questions focused on how they perceived a person with their own occupation. It was assumed that this would elicit the participants' social identity as a professional, i.e., that they implicitly invested at least some part of themselves in their ratings, which is considered necessary for a stereotype threat to occur (Quinn et al., 2013). It is of course possible that they included all other people they know about with the same occupation as themselves, except themselves, or even answered from a general gender-free perspective. As mentioned above, it is not possible to know how much of themselves they invested in their occupational role when asked, and further research is needed in order to establish if stereotype threat, and how to overcome it, is a plausible explanation at all for results like the present ones. However, previous research has shown that people tend to perceive of various male and female roles according to general stereotypes (Eagly et al., 2019; Haines et al., 2016; Zakrisson \& Löfstrand, 2019), and it is highly probable that people are affected by such stereotypes also in the perceptions of their own occupation. This means that the perceived gender proportion in that particular occupation, and the stereotypic associations with which it is equipped probably affect their perceptions. However, further research is needed, with elaborations of combinations of occupations and gender, in order to separate the perceptions of gendered occupations from perceptions of gender, and also in relation to own gender.

That many occupations, especially in the welfare sector, where most of the female dominated occupations are found, have undergone an increasing professionalization means that there may be generational differences in how to perceive of one's occupational role. Accordingly, the female participants would be younger than the male participants, and thus to be more well-educated, which would explain some of the differences in perceptions. However, in Study 1 all participants were of about the same age, between 18 and 30 years, and in Study 2 there were no age differences between the occupational categories, nor in interaction with gender. Consequently, generational effects seem unlikely.

Women are stereotypically expected to be warm and friendly, and women are generally found to be nicer than men (Eagly \& Mladinic, 1994). Maybe this is expressed in the present two studies as women rating their own ingroup (i.e., another person with their own occupation) as more competent. However, research has more often found men to display ingroup favoritism, and women even to display outgroup favoritism (Batalha et al., 2007; Eckes, 2002; Laurin, 2016), so this seems not to be a likely explanation.

A strength in the present research is that educational level was included in the analyses. Education level not only corresponds to competence in an objective sense, it also signals status, authority, etc. (Fiske, 2018). In much research comparing roles more or less associated with gender, such factors have not been taken into consideration. For example, many of the female dominated roles used as stimulus material in many studies differ from the male dominated roles 
included in level of education required or other status markers that not necessarily are dependent on but covary with gender (Froehlich et al., 2020; Koenig \& Eagly, 2014). For example, secretary and geriatric aide have been compared with lawyer and doctor. Given that such occupations require different amounts of formal education, corresponding differences in perceived competence are very likely. In the present research, educational leveling was controlled for. The unexpected difference between men and women's perceptions of competence were consistent both for people with a high school education and for people with a university degree.

\section{Conclusion}

This research started with a well-founded assumption that women face stereotype threats in their work roles, and that this would be displayed as lower ratings of how they thought other people to perceive the competence of their own occupational roles, compared to men. This was not found. What was consistent across the two studies was that women rated the competence of their own occupation as significantly higher than men did, regardless of educational level or area of work. This was not expected. Either there would be no differences, or if differences were to be found, men would display higher ratings than women, due to them having more confidence in their performance (Bench et al., 2015; Tellhed et al., 2017). A limitation is that the design of these two studies did not make it possible to penetrate whether the unexpected results are due to a strategy to counteract possible stereotype threat, or if stereotype threat is an underlying dynamic here at all. However, alternative explanations, such as the covariation between gender, on the one hand, and age and competence in an objective sense, i.e., educational level, on the other hand, could be ruled out.

What is novel in this research is that, contrary to what was expected, women rated the competence of their occupation higher than men did, in two different studies, with different types of samples, and controlling for several background variables. Why these results emerged is still an open question, and more research is needed, with different designs, different contexts, and different operationalizations of competence, social identity, and stereotype threat. We hope that other researchers find the present results challenging enough to take part in this endeavor.

Acknowledgements The author is indebted to three students, Josefine Holst, Emma Jonsson, and Martina Willners, for valuable contribution to the literature review, data collection, and preliminary data analyses.

Availability of data and material Data will be made available on request.

Authors' contributions There is but one author to the present research, who is fully responsible for all parts of the process, from study conception to the final draft. Three students have contributed to the literature review, data collection, and preliminary data analyses.

Funding information Open access funding provided by Mid Sweden University. The research has been funded by internal grants from Mid Sweden University to the author.

\section{Declarations}

Conflicts of interest The author has no relevant financial or non-financial interests to declare.

Code availability Not applicable

Ethics approval Study 1 was subjected to an application for ethical approval from the Research Ethics Authority [Etikprövningsmyndigheten], Decision No. 2017/456-31. The decision stated that the Research Ethics Act (SFS 2003:460) was not applicable to the project, and the Authority declared that they did not find any ethical problems with the intended research. As Study 2 was a direct replication of Study 1 , no additional application was made.

Participants consent and consent to publish All participants were provided with written information describing the aim of the study, how the study was carried out, and how data was to be handled and reported. It was stressed that participation was voluntary and anonymous. It was explicitly mentioned that by turning to the next page (or returning the paper version of the questionnaire in the pre-paid envelope) they consented to participation. By this procedure, the participants consented to both participation and publication.

Open Access This article is licensed under a Creative Commons Attribution 4.0 International License, which permits use, sharing, adaptation, distribution and reproduction in any medium or format, as long as you give appropriate credit to the original author(s) and the source, provide a link to the Creative Commons licence, and indicate if changes were made. The images or other third party material in this article are included in the article's Creative Commons licence, unless indicated otherwise in a credit line to the material. If material is not included in the article's Creative Commons licence and your intended use is not permitted by statutory regulation or exceeds the permitted use, you will need to obtain permission directly from the copyright holder. To view a copy of this licence, visit http://creativecommons.org/licenses/by/4.0/.

\section{References}

BarNir, A. (2021). To venture or not to venture? Gender stereotyping and women's entrepreneurial aspirations. Sex Roles, 85, 57-72. https://doi.org/10.1007/s11199-020-01204-3

Barreto, M., Ellemers, N., Cihangir, S., \& Stroebe, K. (2008). The selffulfilling effects of contemporary sexism: How it affects women's well-being and behavior. In M. Barreto, M. Ryan, \& M. Schmitt (Eds.), The glass ceiling in the $21^{\text {st }}$ century: Understanding barriers in gender inequality (pp. 99-123). American Psychological Association.

Barreto, M., Ellemers, N., Piebinga, L., \& Moya, M. (2010). How nice of us and how dumb of me: The effects of exposure to benevolent sexism on women's tasks and relational self-descriptions. Sex Roles, 62, 532-544. https://doi.org/10.1007/s11199-009-9699-0 
Batalha, L., Akrami, N., \& Ekehammar, B. (2007). Outgroup favoritism: The role of power perception, gender, and conservatism. Current Research in Social Psychology, 13(4), 38-49.

Bench, S. W., Lench, H. C., Liew, J., Miner, K., \& Flores, A. A. (2015). Gender gaps in overestimation of maths performance. Sex Roles, 72, 536-546. https://doi.org/10.1007/s11199-015-0486-9

Bergeron, D. M., Block, C. J., \& Echtenkamp, B. A. (2006). Disabling the able: Stereotype threat and women's work performance. Human Performance, 19(2), 133-158. https://doi.org/10.1207/ s15327043hup1902_3

Bonnot, V., \& Jost, J. T. (2014). Divergent effects of system justification salience on the academic self-assessments of men and women. Group Processes \& Intergroup Relations, 17(4), 453464. https://doi.org/10.1177/1368430213512008

Brescoll, V. L. (2016). Leading with their hearts? How gender stereotypes of emotion lead to biased evaluations of female leaders. The Leadership Quarterly, 27, 415-428. https://doi.org/10.1016/j. leaqua.2016.02.005

Chalabaev, A., Stone, J., Sarrazin, P., \& Croizet, J. C. (2008). Investigating physiological and self-reported mediators of stereotype lift effects on a motor task. Basic and Applied Social Psychology, 30, 18-26. https://doi.org/10.1080/01973530701665256

Crosby, F., Bromley, S., \& Saxe, L. (1980). Recent unobtrusive studies of Black and White discrimination and prejudice: A literature review. Psychological Bulletin, 87(3), 546-563. https://doi.org/ 10.1037/0033-2909.87.3.546

Cuddy, A. J. C., Fiske, S. T., \& Glick, P. (2004). When professionals become mothers, warmth doesn't cut the ice. Journal of Social Issues, 60(4), 701-718. https://doi.org/10.1111/j.0022-4537.2004. 00381.x

Devine, P. G. (1989). Stereotypes and prejudice: Their automatic and controlled components. Journal of Personality and Social Psychology, 56, 5-18. https://doi.org/10.1037/0022-3514.56.1.5

Eagly, A. H., \& Karau, S. J. (2002). Role congruity theory of prejudice toward female leaders. Psychological Review, 109, 573-598. https://doi.org/10.1037/0033-295X.109.3.573

Eagly, A. H., \& Mladinic, A. (1994). Are people prejudiced against women? Some answers from research on attitudes, gender stereotypes, and judgments of competence. In W. Stroebe \& M. Hewstone (Eds.), European Review of Social Psychology, 5 (pp. 1-35). Wiley.

Eagly, A. H., Nater, C., Miller, D. I., Kaufmann, M., \& Sczesny, S. (2019). Gender stereotypes have changed: A cross-temporal metaanalysis of U.S. public opinion polls from 1946 to 2018. American Psychologist, 75(3), 301-315. https://doi.org/10.1037/amp00 00494

Eagly, A. H., Wood, W., \& Diekman, A. B. (2000). Social Role Theory of sex differences and similarities: A current appraisal. In T. Eckes \& H. M. Trautner (Eds.), The developmental social psychology of gender (pp. 123-174). Erlbaum.

Eckes, T. (2002). Paternalistic and envious gender stereotypes: Testing predictions from the Stereotype Content Model. Sex Roles, 47(3/4), 99-114. https://doi.org/10.1023/A:1021020920715

Ellemers, N. (2018). Gender stereotypes. Annual Review of Psychology, 69, 275-298. https://doi.org/10.1146/annur ev-psych-122216-011719

Fiske, S. T. (2014). Social beings: Core motives in social psychology. Wiley.

Fiske, S. T. (2018). Stereotype content: Warmth and competence endure. Current Directions in Psychological Science, 27(2), 67-73. https://doi.org/10.1177/0963721417738825

Fiske, S. T., Cuddy, A. J. C., Glick, P., \& Xu, J. (2002). A model of (often mixed) stereotype content: Competence and warmth respectively follow from perceived status and competition. Journal of Personality and Social Psychology, 82(6), 878-902. https://doi. org/10.1037/0022-3514.82.6.878
Fiske, S. T., Cuddy, A. J. C., \& Glick, P. (2007). Universal dimensions of social cognition: Warmth and competence. Trends in Cognitive Science, 11(2), 77-83. https://doi.org/10.1016/j.tics.2006.11.005

Froehlich, L., Olsson, M. I. T., Dorrough, A. R., \& Martiny, S. E. (2020). Gender at work across nations: Men and women working in male-dominated and female-dominated occupations are differently associated with agency and communion. Journal of Social Issues, 76(3), 484-511. https://doi.org/10.1111/josi.12390

Glen, S. (2020). Fmax/Hartley's Test: Definition, step by step example, table. From StatisticsHowTo.com: Elementary statistics for the rest of us! Retrieved from https://www.statisticshowto.com/ fmax.hartleys-test.

Glick, P., \& Fiske, S. T. (2001). Ambivalent sexism. In M.P. Zanna (Ed.). Advances in Experimental Social Psychology, 33, 115-188.

Glick, P., Fiske, S. T., Mladinic, A., Saiz, J. L., Abrams, D., et al. (2000). Beyond prejudice as simple antipathy: Hostile and benevolent sexism across cultures. Journal of Personality and Social Psychology, 79, 763-775. https://doi.org/10.1037/0022-3514. 79.5.763

Haines, E. L., Deaux, K., \& Lofaro, N. (2016). The times they are a-changing ... or are they not? A comparison of gender stereotypes, 1983-2014. Psychology of Women Quarterly, 40(3), 353363. https://doi.org/10.1177/0361684316634081

Haynes, M., \& Heilman, M. E. (2013). It had to be you (not me)! Women's attributional rationalization of their contribution to successful joint work outcomes. Personality and Social Psychology Bulletin, 39(7), 956-969. https://doi.org/10.1177/0146167213486358

Heilman, M. E. (2001). Description and prescription: How gender stereotypes prevent women's ascent up the organizational ladder. Journal of Social Issues, 57(4), 657-674. https://doi.org/10.1111/ 0022-4537.00234

Heilman, M. E. (2012). Gender stereotypes and workplace bias. Research in Organizational Behavior, 32, 113-135. https://doi. org/10.1016/j.riob.2012.11.003

Heilman, M. E., \& Eagly, A. (2008). Gender stereotypes are alive, well, and busy producing workplace discrimination. Industrial and Organizational Psychology, 1, 393-398. https://doi.org/10. 1111/j.1754-9434.2008.00072.x

Heilman, M. E., \& Okimoto, T. G. (2008). Motherhood: A potential source of bias in employment decisions. Journal of Applied Psychology, 93(1), 189-198. https://doi.org/10.1037/0021-9010.93.1. 189

Hentschel, T., Heilman, M., \& Peus, C. V. (2019). The multiple dimensions of gender stereotypes: A current look at men's and women's characterizations of others and themselves. Frontiers in Psychology, 10, 1-19. https://doi.org/10.3389/psyg.2019.00011

Hoffman, A., \& Musch, J. (2019). Prejudice against women leaders: Insights from an indirect questioning approach. Sex Roles, 80, 681-692. https://doi.org/10.1007/s11199-018-0969-6

Hoyt, C. L., \& Blascovich, J. (2007). Leadership efficacy and women leaders' responses to stereotype activation. Group Processes and Intergroup Relations, 10(4), 595-616. https://doi.org/10.1177/ 1368430207084718

Hoyt, C. L., \& Murphy, S. E. (2016). Managing to clear the air: Stereotype threat, women, and leadership. The Leadership Quarterly, 27, 387-399. https://doi.org/10.1016/j.leaqua.2015.11.002

Joshi, A., Son, J., \& Roh, H. (2015). When can women close the gap? A meta-analytical test of sex differences in performance and rewards. Academy of Management Journal, 58(5), 1516-1545. https://doi.org/10.5465/amj.2013.0721

Koenig, A. M., \& Eagly, A. H. (2005). Stereotype threat in men on a test of social sensitivity. Sex Roles, 52(7/8), 489-496. https://doi. org/10.1007/s1199-005-3714-x

Koenig, A. M., \& Eagly, A. H. (2014). Evidence for the social role theory of stereotype content: Observations of groups' roles shape 
stereotypes. Journal of Personality and Social Psychology, 107(3), 371-392. https://doi.org/10.1037/a0037215

Koenig, A. M., Eagly, A. H., Mitchell, A. A., \& Ristikari, T. (2011). Are leader stereotypes masculine? A meta-analysis of three research paradigms. Psychological Bulletin, 137(4), 616-642. https://doi.org/10.1037/a0023557

Kray, L. J., Galinsky, A. D., \& Thompson, L. (2002). Revising the gender gap in negotiations: An exploration of stereotype regeneration. Organizational Behavior and Human Decision Processes, 87(2), 386-409. https://doi.org/10.1006/obhd.2001.2979

Latsch, M., \& Hannover, B. (2014). Smart girls, dumb boys!? How the discourse on "failing boys" impacts performances and motivational goal orientation on German school students. Social Psychology, 45(2), 112-126. https://doi.org/10.1027/1864-9335/ a000167

Latu, I. M., Schmid Mast, M., \& Stewart, T. L. (2015). Gender biases in (inter) action: The role of interviewers' and applicants' implicit and explicit stereotypes in predicting women's job interview outcomes. Psychology of Women Quarterly, 39(4), 539-552. https:// doi.org/10.1177/0361684315577383

Laurin, R. (2016). Awareness level of gender sterotype and stereotype threat effect on ingroup favoritism bias in mixed-gender basketball teams. Canadian Journal of Behavioural Science, 48(2), 155-161. https://doi.org/10.1037/cbs0000039

Martens, A., Johns, M., Greenberg, J., \& Schimel, J. (2006). Combating stereotype threat: The effect of self-affirmation on women's intellectual performance. Journal of Experimental Social Psychology, 42, 236-243. https://doi.org/10.1016/j.jesp.2005.04.010

Marx, D. M., \& Stapel, D. A. (2006). Understanding stereotype lift: On the role of the social self. Social Cognition, 24(6), 776-791. https://doi.org/10.1521/soco.2006.24.6.776

Marx, D. M., Stapel, D. A., \& Muller, D. (2005). We can do it: The interplay of construal orientation and social comparison under threat. Journal of Personality and Social Psychology, 88, 432446. https://doi.org/10.1037/0022-3514.88.3.432

McGlone, M. S., \& Aronson, J. (2007). Forewarning and forearming stereotype-threatened students. Communication Education, 56, 119-133. https://doi.org/10.1080/03634520601158681

McIntyre, R. B., Paulson, R. M., \& Lord, C. G. (2003). Alleviating women's mathematic stereotype threat through salience of group achievements. Journal of Experimental Social Psychology, 39, 83-90. https://doi.org/10.1016/S0022-1031(02)00513-9

Meeussen, L., Van Laar, C., \& Van Grootel, S. (2020). How to foster male engagement in traditionally female communal roles and occupations: Insights from research on gender norms and precarious manhood. Social Issues and Policy Review, 14(1), 297-328. https://doi.org/10.1111/sipr.12060

Quinn, D. M., Kallen, R. W., \& Spencer, S. J. (2013). Stereotype threat. In J. F. Dovidio, M. Hewstone, P. Glick, \& V. M. Esses (Eds.), The SAGE handbook of prejudice, stereotyping and discrimination (pp. 379-395). Los Angeles, CA: SAGE Publications.
Schmitt, M. T., Branscombe, N. R., Postmes, T., \& Garcia, A. (2014). The consequences of perceived discrimination for psychological well-being: A meta-analytic review. Psychological Bulletin, 140, 921-948. https://doi.org/10.1037/a0035754

Sherman, D. K., Hartson, K. A., Binning, K. R., Purdie-Vaughns, V., Garcia, J., Taborsky-Barba, S., et al. (2013). Deflecting the trajectory and changing the narrative: How self-affirmation affects academic performance and motivation under identity threat. Journal of Personality and Social Psychology, 104(4), 591-618. https:// doi.org/10.1037/a0031495

Statistics Sweden. (2018). På tal om kvinnor och män [Women and men in Sweden: Facts and figures]. Statistics Sweden.

Steele, C. M., \& Aronson, J. (1995). Stereotype threat and the intellectual test performance of African Americans. Journal of Personality and Social Psychology, 69(5), 797-811. https://doi.org/ 10.1037/0022-3514.69.5.797

Tellhed, U., \& Adolfsson, C. (2018). Competence and confusion: How stereotype threat can make you a bad judge of your competence. European Journal of Social Psychology, 48, 0189-0197. https:// doi.org/10.1002/ejsp.2307

Tellhed, U., \& Björklund, F. (2011). Stereotype threat in salary negotiations is mediated by reservation salary. Scandinavian Journal of Psychology, 52(2), 185-195. https://doi.org/10.1111/j.1467-9450. 2010.00855.x

Tellhed, U., Bäckström, M., \& Björklund, F. (2017). Will I fit in and do well? The importance of social belongingness and self-efficacy for explaining gender differences in interest in STEM and HEED majors. Sex Roles, 77, 86-96. https://doi.org/10.1007/ s11199-016-0694-y

UNDP (2021). Gender Inequality Index (GII) 2020. Human development reports. Retrieved from http://hdr.undp.org/en/content/gender-inequality-index-gii.

van Veelen, R., Derks, B., \& Endedijk, M. D. (2019). Double trouble: How being outnumbered and negatively stereotyped threatens career outcomes of women in STEM. Frontiers in Psychology, 10, 1-18. https://doi.org/10.3389/psyg.2019.00150

Veldman, J., Meeussen, L., Van Laar, C., \& Phalet, K. (2017). Women (do not) belong here: Gender-work identity conflict among female police officers. Frontiers in Psychology, 8, 1-12pp. doi: 10.3389/ psyg.2017.00130

Vial, A. C., Napier, J. L., \& Brescoll, V. L. (2016). A bed of thorns: Female leaders and the self-reinforcing cycle of illegitimacy. The Leadership Quarterly, 27, 400-414. https://doi.org/10.1016/j. leaqua.2015.12.004

Zakrisson, I., \& Löfstrand, P. (2019). Stereotypic perceptions of occupations: Being a woman, well-educated and nice does not pay. Paper presented at the International Interdisciplinary Conference on HRM, Gothenburg April 3-5, 2019.

Publisher's note Springer Nature remains neutral with regard to jurisdictional claims in published maps and institutional affiliations. 